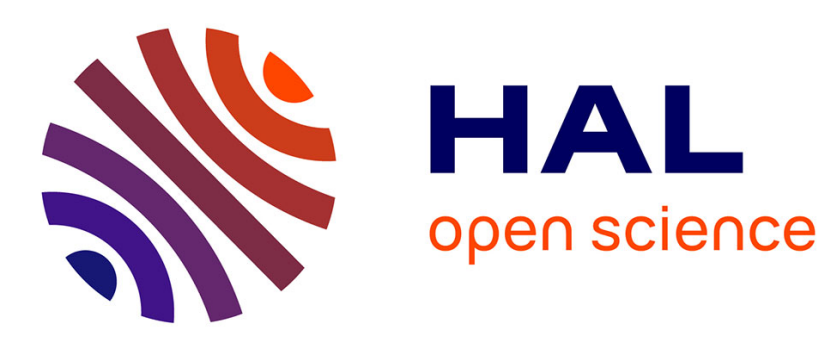

\title{
Hydrofluorination of Alkenes: A Review
}

Xavier Bertrand, Laurent Chabaud, Jean-françois Paquin

\section{To cite this version:}

Xavier Bertrand, Laurent Chabaud, Jean-françois Paquin. Hydrofluorination of Alkenes: A Review. Chemistry - An Asian Journal, 2021, 16 (6), pp.563-574. 10.1002/asia.202001403 . hal-03358270v2

\section{HAL Id: hal-03358270 \\ https://hal.science/hal-03358270v2}

Submitted on 8 Oct 2021

HAL is a multi-disciplinary open access archive for the deposit and dissemination of scientific research documents, whether they are published or not. The documents may come from teaching and research institutions in France or abroad, or from public or private research centers.
L'archive ouverte pluridisciplinaire HAL, est destinée au dépôt et à la diffusion de documents scientifiques de niveau recherche, publiés ou non, émanant des établissements d'enseignement et de recherche français ou étrangers, des laboratoires publics ou privés. 


\section{Hydrofluorination of Alkenes}

Xavier Bertrand ${ }^{[a]}$, Laurent Chabaud ${ }^{[b]}$ and Jean-François Paquin ${ }^{*[a]}$

((Insert Picture for Frontispiece here [18.0×18.0 cm])) 
[a] X. Bertrand, Prof. J.-F. Paquin

CCVC, PROTEO, Département de chimie

Université Laval

1045 avenue de la Médecine, Québec, QC, Canada, G1V 0A6

E-mail: jean-francois.paquin@chm.ulaval.ca

[b] Dr. L. Chabaud

Institut des Sciences Moléculaires

IECB, 2 Rue Robert Escarpit

33600 Pessac, France

Abstract: In this minireview, we explore the different approach used to perform the hydrofluorination reaction of alkenes. Contrary to other hydrohalogenation reactions, the hydrofluorination requires specific conditions due to the lower reactivity of HF. Over the years, many different approaches have been explored. The use of HF complexes has provided easier to handle reagents. Using electrophilic source of fluorine has allowed for enantioselective hydrofluorination, while radical fluorination proved compatible with a vast range of functional groups that are generally problematic with strong acids and some fluoride sources. This review will cover the different conditions developed through the years, starting with the first reported addition using gaseous HF, up to the most recent method described in October 2020.

\section{Introduction}

The interest of fluorine in numerous fields of chemistry is largely recognized especially in pharmaceuticals, ${ }^{[1]}$ agrochemicals, ${ }^{[2]}$ and material sciences. ${ }^{[3]}$ This particular interest has led to more and more research group focusing on the development of efficient and economical method of incorporation of fluorine. ${ }^{[4]}$

The hydrofluorination of alkenes represents an efficient and straightforward strategy to perform the incorporation of a single $s p^{3}$ fluorine atom. This type of fluorine represents about $15 \%$ of all fluorinated drugs approved by the FDA. ${ }^{[5]}$ This transformation can the separated into three main categories based on the general pathway of the addition (Scheme 1). Nucleophilic hydrofluorination proceed via an acidic proton combined with a nucleophilic fluoride. Electrophilic hydrofluorination will generally be achieved with the use a hydride and a " $F$ " source. Finally, radical hydrofluorination can be achieved using a radical source of fluorine usually activated by a transition metal.

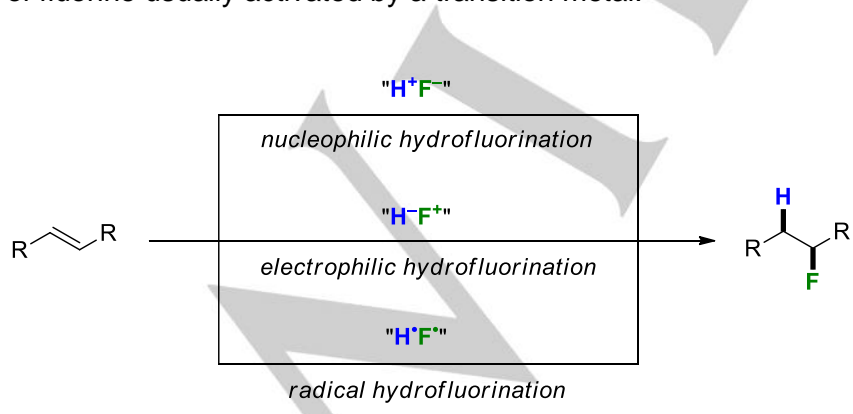

Scheme 1. General pathways of hydrofluorination of alkenes.

In this review, the different methods developed through the years will be described and discussed. To the best of our knowledge, this represents an exhaustive report on the subject, which has never been done before.

Xavier Bertrand was born in Québec City Canada in 1996. He pursued undergraduate studies in chemistry from 2015 to 2018 at Université Laval, during which he studied a semester at Université de Strasbourg. He undertook graduate studies under the supervision of Prof. Jean-François Paquin in 2018. Since 2020, his Ph.D. is under the cosupervision of Prof. Jean-François Paquin and Dr. Laurent Chabaud. His research focuses on the formation of the $\mathrm{C}-\mathrm{F}$ bond with a particular interest for flow chemistry.

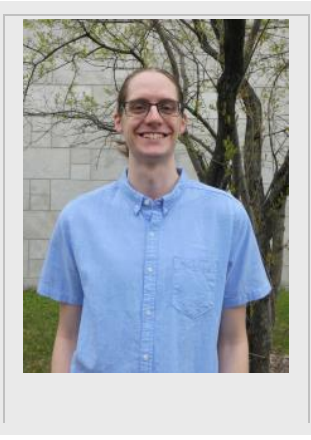

Laurent Chabaud received his $\mathrm{PhD}$ degree in 2005 at Bordeaux University under the supervision of Prof. Y. Landais and Prof. P. Renaud (Bern, CH). In 2006, he joined the group of Prof. J. Clayden in Manchester for postdoctoral studies, then moved to the ICSN (Gif sur Yvette), where he was appointed CNRS researcher in 2008. In 2018 he joined the group of Dr M. Pucheault at the Institute of Molecular Sciences (Bordeaux). His current research interests are dealing with the chemistry of organoboron compounds and their applications, especially in materials science.

Jean-François Paquin received his $\mathrm{PhD}$ in 2004 from the University of Toronto under the supervision of Prof. Mark Lautens. After a postdoctoral stay in Prof. Erick M. Carreira's lab at the ETH Zürich, he was appointed assistant professor in 2005 at the Université Laval in Quebec City. He was promoted to associate professor in 2010 to full professor in 2014. His research interests include the development of novel methodologies for the synthesis of organofluorine compounds and their applications for the preparation of

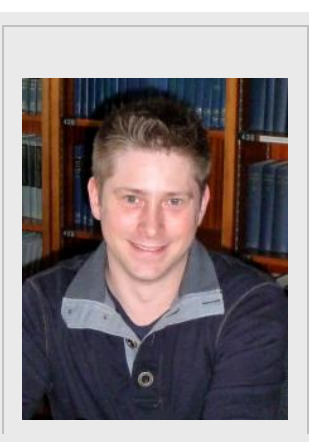
ce. bioactive fluorinated compounds or fluorinated biological probes. In 2016, he was awarded the Keith Fagnou Award from the Canadian Society for Chemistry. 


\section{Nucleophilic hydrofluorination}

Theoretically, the most straightforward and atom economical way to perform an hydrofluorination is with hydrogen fluoride. However, this reagent poses many issues. Not only is it an extremely toxic gas, it also has many chemical incompatibilities, mainly in glassware, and require specific handling precautions. One example was still described by Grosse and Linn in 1938. ${ }^{[6]}$ Anhydrous hydrogen fluoride was condensed in an autoclave with ethylene or propylene to afford the corresponding fluorides (Scheme 2). The impracticability of these conditions on laboratory-scale as well as the rising concern on security urged chemists to developed safer alternatives. One of the main research axes investigated is the complexation of hydrogen fluoride on different molecules to obtain either a liquid or a solid, that significantly reduce the risk.

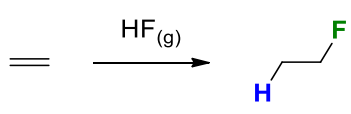

Scheme 2. Anhydrous hydrogen fluoride addition on ethylene reported by Grosse and Linn in 1938.

In 1973, Olah and coworkers reported the first hydrofluorination of alkenes without the direct use of HF. ${ }^{[7]}$ The reagent they used, now known as the Olah reagent, is a complex of $70 \%$ hydrogen fluoride in pyridine. This reagent allowed the fluorination of simple, unfunctionalized alkenes (Scheme 3). In 1983, Yoneda showed that using melamine as the amine instead of pyridine raised the stability of the complex. ${ }^{[8]}$ In 1990 , Olah used a solid-supported version of his reagent, poly-4-vinylpyridinium poly(hydrogenfluoride) (PVP-HF), which contains between $35 \%$ and $60 \%$ of hydrogen fluoride in weight, to perform the hydrofluorination of the same alkenes. ${ }^{[9]}$ One of the main advantages of this reaction was the nature of the reagent, which is a solid, that allowed for a safer handling of hydrogen fluoride and better purification. Finally, Olah developed a complex of hydrogen fluoride on dimethyl ether. The complex can be made from one to five equivalents of HF on the ether and allows for a variety of fluorination reaction including the hydrofluorination of alkenes. It was shown that 5 equivalents of HF gave the best yields. ${ }^{[10]}$

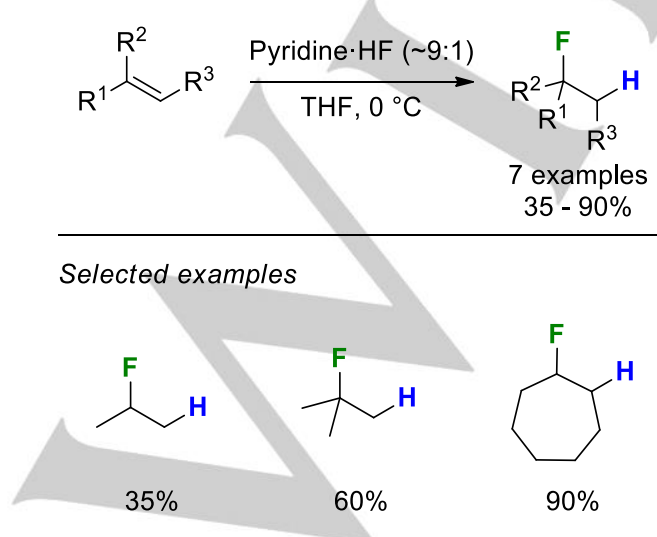

Scheme 3. Hydrofluorination of simple alkenes using pyridine HF by Olah and coworkers.
In 1995, Sekiya reported that a mixture of $\mathrm{KHF}_{2}$ and $\mathrm{SiF}_{4}$ was able to produce the fluoroalkyl compounds, although the mechanism was not clearly defined (Scheme 4). ${ }^{[11]}$

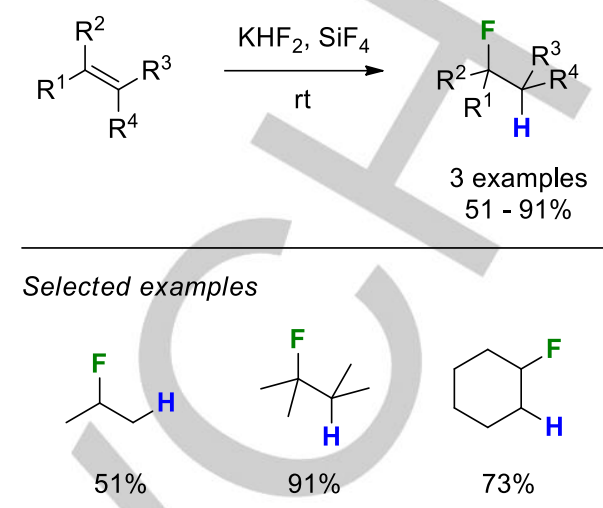

Scheme 4. Sekiya's conditions for the hydrofluorination of simple alkene.

In 1996, Yoneda and coworkers reported the first conditions that tolerated functionalized alkenes. Using a complex of 5 or 6 hydrogen fluoride on triethylamine, they were able to hydrofluorinate alkenes in the presence of ketone, alcohol, and ester. $^{[12]}$

Table 1. Composition of the different complexes used by Olah and Yoneda.

\begin{tabular}{ccc}
\hline Molecule & HF quantity ${ }^{[a]}$ & Molar ratio \\
\hline Pyridine (1) & $70 \%$ & $\sim 9: 1$ \\
Triethylamine (2) & $50 \%-54 \%$ & $5: 1 / 6: 1$ \\
Dimethyl ether (3) & $68 \%$ & $5: 1$ \\
Poly-4-vinylpyridine (4) & $60 \%$ & $7: 1^{[\mathrm{b}]}$ \\
Melamine (5) & $86 \%$ & $\sim 3: 1$
\end{tabular}

[a] \% w/w [b] per unit of 4-vinylpyridine<smiles>c1ccncc1</smiles>

1

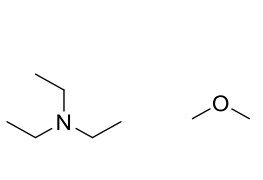

2

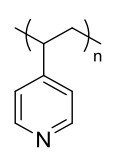

4<smiles>Nc1nc(N)nc(N)n1</smiles>

5
These pioneering conditions were, for a long time, the only efficient way to perform an hydrofluorination reaction on alkenes. However, these conditions still required a very large excess of reagent and were only applied to simple alkenes. In 2007, the group of Thibaudeau reported that the used of a superacid, $\mathrm{HF} \cdot \mathrm{SbF}_{5}$, allowed the fluorination of allylic amines (Scheme 5). ${ }^{[13]}$ This represents a great way of obtaining $\beta$-fluoroamines. The reaction, proceeding through a dicationic mechanism, showed great selectivity in the case of a higher percentage of HF. 
However, as the fraction of antimony pentafluoride rose, many undesired products were formed. The best results were obtained using a 7:1 $\mathrm{HF}: \mathrm{SbF}_{5}$ mixture.
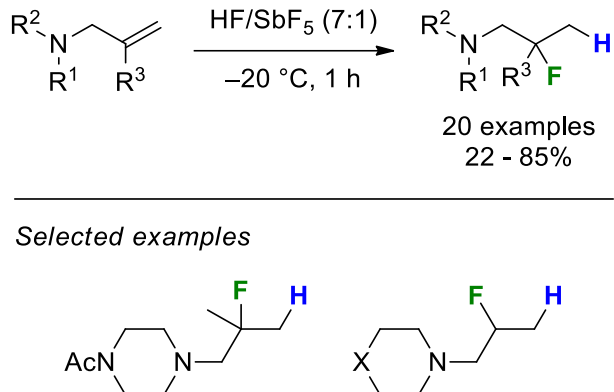

$85 \%$

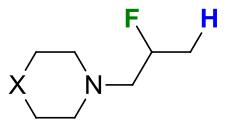

$\mathrm{X}=\mathrm{NH}, 57 \%$

$\mathrm{X}=\mathrm{NBn}, 85 \%$

$\mathrm{X}=\mathrm{CO}, 70 \%$<smiles>CC(F)CNS(=O)(=O)c1ccc([N+](=O)[O-])cc1</smiles>

$74 \%$

Scheme 5. Synthesis of $\beta$-fluoroamines reported by Thibaudeau and coworkers

The reaction works well for amines and sulfonamides, but amides produce the hydroxylated product. This is hypothesized to be due to the longer distance between the dication, which reduces its electrophilicity. Amides are indeed protonated at the oxygen instead of the nitrogen on amines or sulfonamides (Figure 1). This is also the case for homoallylic amines that give lower yields. When the distance was longer between the dication, no fluorinated product was observed.<smiles>[R][NH+]([R])CCCC</smiles><smiles>[R]C(=[OH+])N(C)C[CH-]C</smiles><smiles>[R]N(CC[CH+]C)S([R])(=O)=O</smiles>

Figure 1. Dicationic intermediates of different functional groups after reacting with $\mathrm{HF} \cdot \mathrm{SbF}_{5}$ complex.

In a subsequent paper, they showed that diallyl amines could produce various fluorinated piperidines under similar reaction conditions. ${ }^{[14]}$ The reaction proceeds via a protonation, cyclisation, and fluorination sequence (Scheme 6). Interestingly, pyrrolidines could be obtained starting from methyl substituted allyl amines, although the precise mechanism remains unclear.

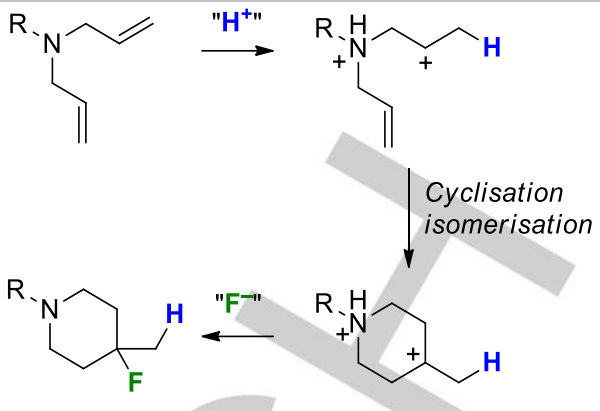

Scheme 6. Proposed mechanism for the preparation of fluorinated piperidine from diallylamines.

Then, in 2017, an important breakthrough was accomplished in the field of nucleophilic hydrofluorination with the work of Hammond and coworkers. ${ }^{[15]}$ By reacting anhydrous hydrogen fluoride with potassium bisulfate, they were able to synthesis a new reagent, $\mathrm{KHSO}_{4} \cdot 13 \mathrm{HF}$. This reagent is bench-stable, easyto-handle, and, now, commercially available. One of its main advantage is that, compared to amine complex, it remains acidic due to the presence of the proton on the bisulfate. It also possesses a strong $\mathrm{H}$-bond acceptor that can complex many hydrogen fluorine molecules. This allows for a bifunctionalization of the alkene with the same reagent delivering the proton and the fluoride.

This significant contribution was the first nucleophilic method to use near stoichiometric reagent with a wide range of substrates and functional group. Mono-, di- and trisubstituted alkenes all react to afford the corresponding compounds in good yields (Scheme 7). Free alcohols, amines and carboxylic acids were all compatible without any significant drop in yield. The reagent also shows a great chemioselectivity, not reacting with alkynes and only with the more nucleophile alkene when two are present. Although the reagent was synthesized by the group for the first time, it is now commercially available.

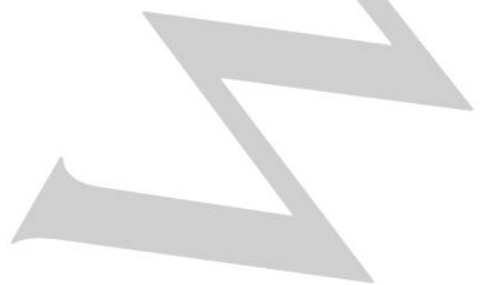




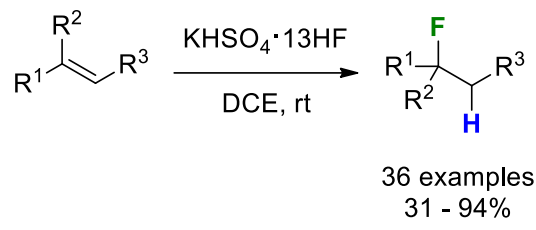<smiles>CC(F)CCCOC(=O)OCc1ccccc1</smiles>

$83 \%$<smiles>C#CCCCC(=O)OCCCC(C)F</smiles>

Scheme 7. Hydrofluorination conditions developed by Hammond and coworkers.

In another paper published in 2019, they developed a solid version of their reagent. ${ }^{[16]}$ By adding gaseous hydrogen fluoride on anionic resins, they were able to synthesis a solid equivalent of HF. After testing different commercially available resins, they found out that the Amberlyst A26, bearing a quaternary ammonium was the best candidate. They first reacted the resin with sulfuric acid to replace the hydroxide counterion with a bisulfate, after which they added hydrogen fluoride to furnish the resin-supported $\mathrm{HF}$ at $30 \% \mathrm{w} / \mathrm{w}$ concentration. This resin was used in the reaction of hydrofluorination of various alkenes. It showed better reactivity and a higher quantity of HF per gram of resin than other tested resins e.g., one bearing a free amine and one bearing a sulfonate. The reaction is compatible with di- and trisubstituted alkenes, but monosubstituted alkenes did not react. A wide range of functional groups were tested and shown great yields (Scheme 8). Interestingly, free alcohol and heteroaromatics were tolerated, although the latter needed longer reaction time when a basic moiety was present. By comparing this resin with the PVP-HF developed by Olah, they showed that the yields were higher, and the cost smaller.

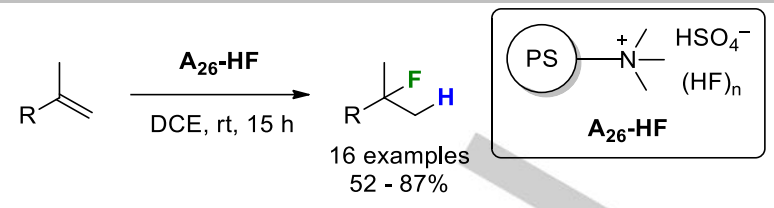

Selected examples<smiles>CC(C)(F)CCOC(=O)c1cccnc1</smiles><smiles>CC(C)(F)CCn1nc2ccccc2n1</smiles>

$85 \%$ $56 \%$

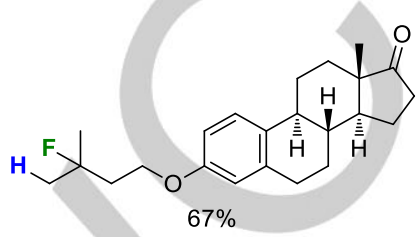

Scheme 8. Batch hydrofluorination conditions developed by Hammond and coworkers using a resin-supported HF reagent.

With this solid version of HF in hand, they were able to develop a continuous flow system. This is the first example of an hydrofluorination in flow chemistry. To achieve this, they used a packed bed reactor that they filled with their resin. A solution of the alkene is then passed through the column at a $0.5 \mathrm{ml}$ per hour flow rate. The corresponding fluorinated compound is obtained in a $92 \%$ yield.

In 2019, Paquin and coworker reported the hydrofluorination of alkenes using a combination of triethylamine trihydrofluoride and methanesulfonic acid. ${ }^{[17]}$ Considering the general mechanism of hydrohalogenation of alkenes, they envisioned that "HF" could be added on an alkene in the same way as $\mathrm{HCl}$ or $\mathrm{HBr}$. However due to the low acidity of HF, an external acid should be used. After screening different acids and fluorides, they were able to identify a combination that afforded the fluorinated compound in good yields. This combination of reagent allowed for a two-step mechanism involving the protonation of the alkene to form a carbocation followed by a nucleophilic attack of a fluoride. These conditions are, however, limited to alkene that forms tertiary carbocation, i.e., 1,1-disubstituted alkenes and trisubstituted alkenes (Scheme 9). The reagents used are all commercially available, cheap, easy-to-handle and safer than the previously reported alternatives. These conditions were used in the development of continuous flow reaction. Preliminary results are reported showing a promising $36 \%$ yield for a residence time of 17 minutes. 


$$
\checkmark \frac{\mathrm{MsOH}, \mathrm{Et}_{3} \mathrm{~N} \cdot 3 \mathrm{HF}}{\mathrm{CH}_{2} \mathrm{Cl}_{2}, \mathrm{rt}}
$$<smiles>CC(F)(F)CCCOC(=O)c1ccc(-c2ccccc2)cc1</smiles>

$78 \%$<smiles>CC(C)(C)CCC(C)(F)CCO[As]</smiles><smiles>[X]OS(=O)(=O)c1ccc[X]1C(=O)OCCC(C)(C)F</smiles>

$\mathrm{X}=\mathrm{S}, 57 \%$
Scheme 9. Hydrofluorination conditions developed by Paquin and coworker.

\section{Electrophilic hydrofluorination}

In electrophilic hydrofluorination, the fluorine is used as the electrophile, i.e. using a " $\mathrm{F}^{+}$" source. Many electrophilic reagents have been developed over the years. The first reagents used were based on O-F, Xe-F and F-F bond (Figure 2, 1-4). ${ }^{[18]}$ They were, however, very reactive, poorly selective or had a poor storage capacity. Nowadays, these have been supplanted by $\mathrm{N}-$ $\mathrm{F}$ bond-based reagent that shows greater selectivity, stability, and safety (Figure 2, 5-7). ${ }^{[19]}$

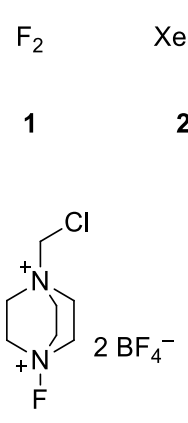

5

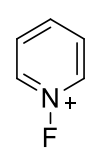

6
$\mathrm{CF}_{3} \mathrm{OF}$

3

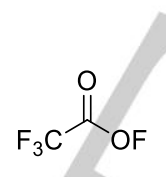

4
Figure 2. Electrophilic fluorination reagents.

MacMillan's group reported in 2005 an organic-cascade catalysis using a mix of iminium and enamine chemistry. ${ }^{[20]}$ This cascade allowed for the incorporation of a nucleophile and an electrophile on the same reaction. This cascade was mainly used to introduce a chlorine and a hydrogen atom onto $\alpha, \beta$-insaturated aldehydes to afford the corresponding $\alpha$-chloro aldehyde. They also presented an example with fluorine using NFSI as the electrophilic source of fluorine and Hantzsch ester as the hydrogen source. Although only three different conditions are reported on (E)-3-phenylbut-2-enal, the ee are all of $99 \%$. Higher yields are obtained when the electrophile is added after complete consumption of the nucleophile.

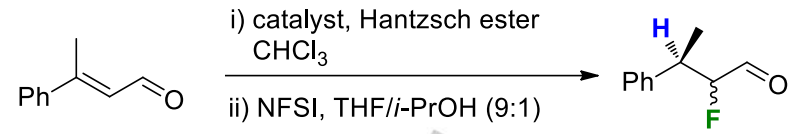

Cond. A : A (20 mol\%)

$60 \%, 99 \%$ ee, $3: 1$ (syn/anti)

Cond. B : A (7.5 mol\%), (R)-B (30 mol\%) $62 \%, 99 \%$ ee, $9: 1$ (synlanti) Cond. C : A (7.5 mol\%), (S)-B (30 mol\%) $81 \%, 99 \%$ ee, $1: 16$ (syn/anti)

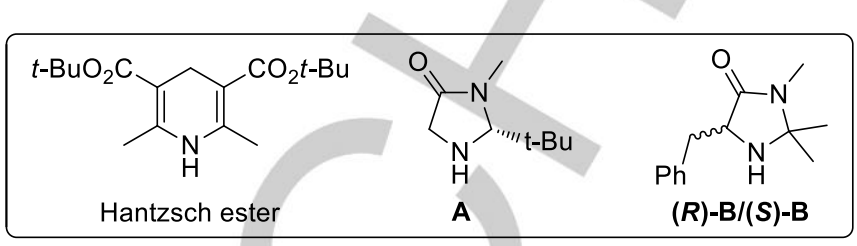

Scheme 10. Hydrofluorination of $(E)$-3-phenylbut-2-enal by enamine-iminium catalysis.

Quite interestingly, the use of two different amine catalysts can be used to significantly raised the diastereoselectivity of the addition from 3:1 syn:anti to 9:1. By changing the enantiomer of one of the catalysts, the product can be obtained in a 16:1 anti:syn selectivity (Scheme 10).

Gouverneur's group was the first to develop an electrophilic hydrofluorination of alkene reaction with a wide scope in 2014. ${ }^{[21]}$ Selectfluor and triethylsilane were used as the source of fluorine and hydride. This reaction is performed using a palladium catalyst and is specific to alkenylarenes. This allows the formation of a wide range of benzylic fluoride (Scheme 11). The mechanism involves the cis-addition of the fluorine and the hydride that was demonstrated using deuterium for isotopic studies.

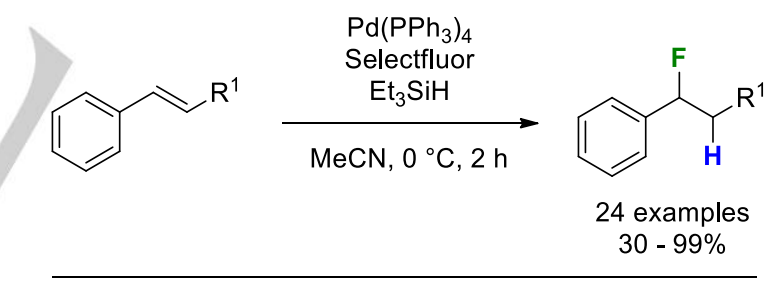

Selected examples

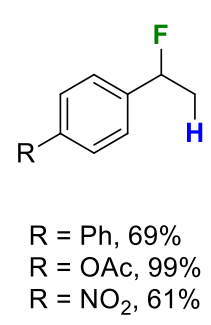<smiles>Cc1ccc(CC(F)C(F)c2ccccc2)cc1</smiles>

Scheme 11. Palladium-catalyzed hydrofluorination of alkenylarenes.

Mechanistic studies showed that Selectfluor was used both to deliver a " $\mathrm{F}^{+}$" and as an oxidant for the catalytic cycle. The proposed mechanism starts with the formation of a $\mathrm{Pd}(\mathrm{II}) \mathrm{H}$ species by activation from the silane. That species performs a syn hydropalladation on the alkenylarene to afford a $\eta^{3}$-benzyl complex. Selectfluor can then oxidize the complex to a 
fluoropalladium (IV) species, which can be reduced via a reductive elimination to afford the cis final product (Figure 3 ).

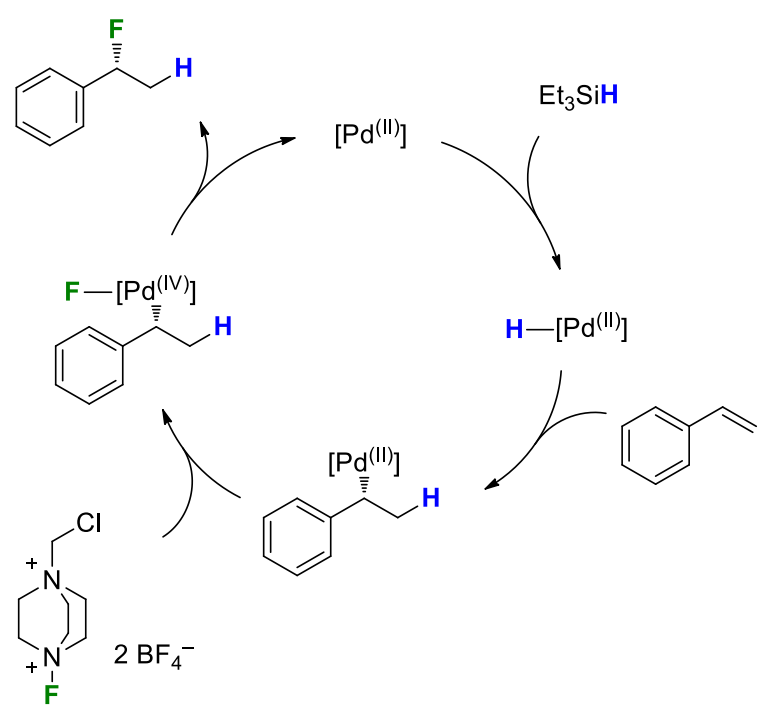

Figure 3. Simplified catalytic cycle proposed by Gouverneur for the cis-addition of HF on alkenylarenes.

Another hydrofluorination reaction, that was developed by Huang and coworkers uses $\mathrm{NHC}$ as a catalyst to perform the reaction. ${ }^{[22]}$ This method enables the hydrofluorination and oxidation of $\alpha, \beta$-insaturated aldehydes to alpha fluoro ester (Scheme 12). The catalyst allows for a sequential $\beta$-protonation followed by an $\alpha$-fluorination. The use of a proton instead of a hydride allows for a greater functional group tolerance and hence a wider range of compatible substrate.
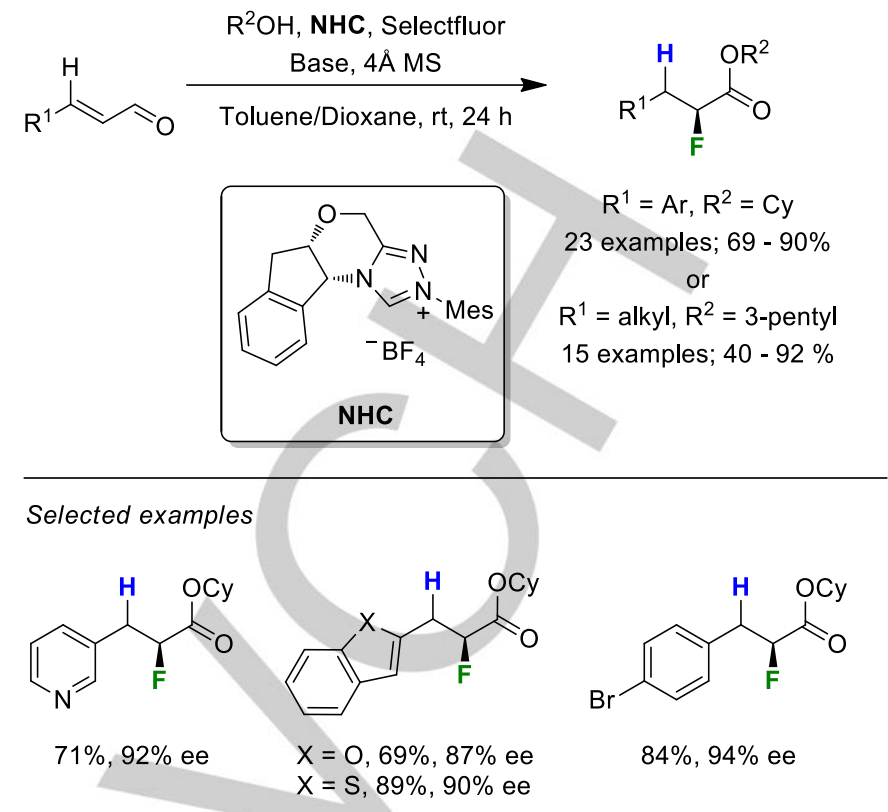<smiles>CCC(CC)OC(=O)[C@H](F)CCCCOC(=O)/C=C/c1ccccc1</smiles>

$82 \%, 90 \%$ ee

$75 \%, 90 \%$ ee

Scheme 12. Hydrofluorination of $\alpha, \beta$-insaturated aldehydes catalyzed by NHC to afford a-fluoro ester.

They exploit the umpolung phenomenon of enals in the presence of $\mathrm{NHC}$ to produce an homoenolate that can be protonate in the presence of an alcohol. The newly formed enolate can then be fluorinated via an electrophilic fluorine source. The catalytic cycle is completed via the attack of the alkoxide on the carbonyl to liberate the $\mathrm{NHC}$ and form the a-fluoro ester (Figure 4). The choice of the alcohol proved critical as it can cause low conversion if not reactive enough, or premature esterification if too reactive. Cyclohexanol was used for aromatic enals, while 3pentanol worked best for aliphatic enals. The use of a chiral NHC allowed for the formation of an enantioenriched center at the C-F bond with excellent ee going from $89 \%$ to $99 \%$. 


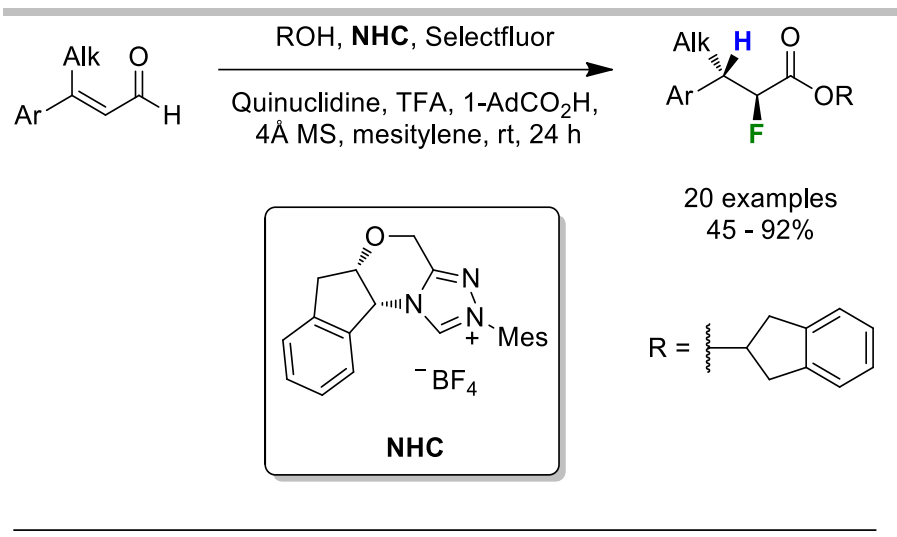

Selected examples<smiles>[R]OC(=O)C(F)[C@H]1CCCc2ccc(Br)cc21</smiles>

$53 \%$

d.r. $>20: 1,>99 \%$ ee

$75 \%$

d.r. $>9.8: 1,>99 \%$ ee<smiles>[R]OC(=O)C(F)[C@@H](C)c1ccc(SC)cc1</smiles><smiles>[R]OC(=O)C(F)[C@H](CCCCOC)c1ccccc1</smiles>

$92 \%$

d.r. $>20: 1,>99 \%$ ee<smiles>[R]OC(=O)C(F)Cc1ccc2c(c1)OCO2</smiles>

$60 \%$
Scheme 13. Hydrofluorination of $\alpha, \beta$-insaturated aldehydes catalyzed by $\mathrm{NHC}$ to afford $\alpha$-fluoro ester.

When using a $\beta$-disubstituted enal, two chiral centres can be created in the same reaction. Once again, a different alcohol must be used, and an acid/base system is used to ensure the optimal delivery rate of the proton. The enantioselectivity and diastereoselectivity are excellent with ee values generally superior to $99 \%$ and d.r. higher than 10:1 (Scheme 13).

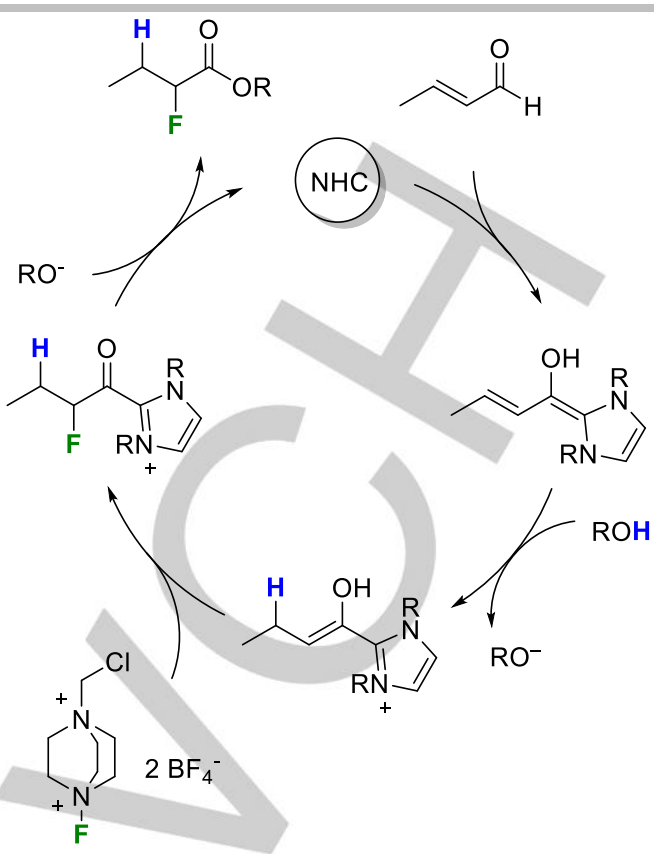

Figure 4. Catalytic cycle proposed by Huang and coworkers for the formation of $\alpha$-fluoro ester from $\alpha, \beta$-insaturated aldehydes.

Finally, Yin and coworkers reported the first efficient enantioselective hydrofluorination of alkenylarenes in 2020. ${ }^{\text {23] }}$ Inspired by Gouverneur's works, they improved the enantioselectivity of the palladium catalyzed reaction. The chirality is induced via a chiral sulfoxide phosphine (SOP) that afford the fluorinated compound with an enantiomeric ratio up to 94:6. The authors performed some NMR studies to propose a catalytic cycle (Figure 5). They found out that the palladium forms a five-member ring with the SOP via the coordination of the sulfur and phosphorous atom. The chirality is induced via an insertion of a $\mathrm{Pd}(\mathrm{II})-\mathrm{H}$ species on the alkene. However, the NMR showed that this species is not stable unless a secondary phosphine is present to stabilize the complex. Finally, a silver salt is used to generate the cationic palladium complex. After screening the different reagents, they identified the optimal conditions shown in scheme 14. 


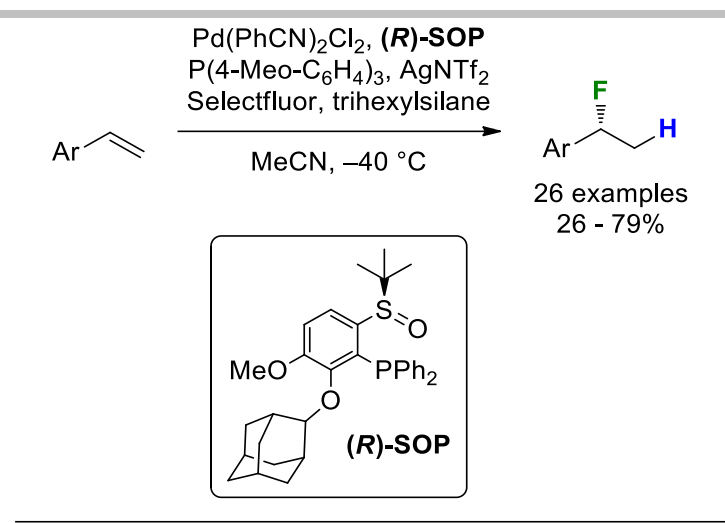

Selected examples<smiles>[R]c1ccc(-c2ccc([C@H](C)F)cc2)cc1</smiles><smiles>[R]c1ccc(C(C)F)cc1</smiles>

$\mathrm{R}=\mathrm{MeO}, 62 \%, 71 \%$ ee $\mathrm{R}=\mathrm{Me}, 72 \%, 81 \%$ ee

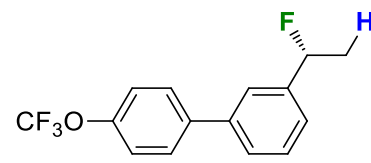

$63 \%, 83 \%$ ee

$$
\mathrm{R}=\mathrm{AcO}, 74 \%, 83 \% \text { ee }
$$$$
\mathrm{R}=\mathrm{BzO}, 72 \%, 86 \% \text { ee }
$$<smiles>NC(=O)c1ccc([C@@H](F)Cc2ccccc2)cc1</smiles>

$58 \%, 83 \%$ ee year, Boger's group reported the first radical hydrofluorination of alkenes. ${ }^{[25]}$ By using iron (III) oxalate, Selectfluor and sodium borohydride, a wide range of alkenes could be converted to the corresponding fluoroalkane. Terminal, di- and trisubstituted alkenes were effectively used for this transformation for an average yield of $63 \%$ (Scheme 15).

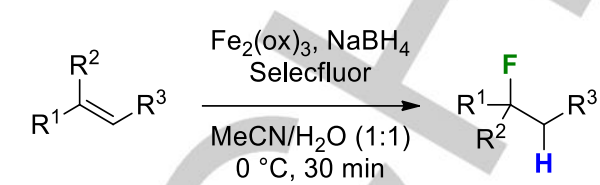

18 examples

$41-79 \%$

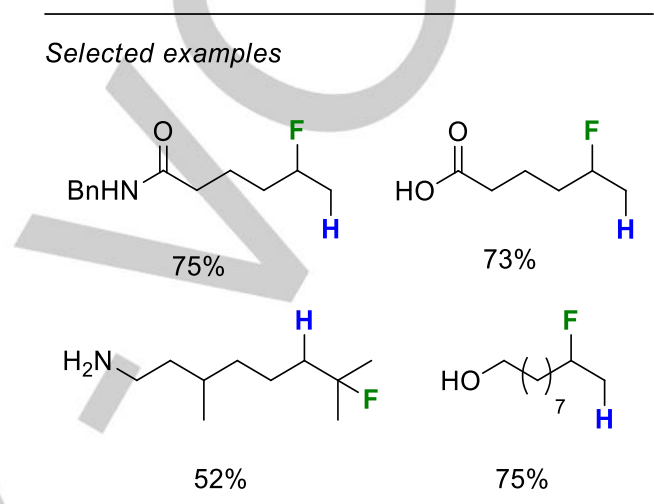

Scheme 15. Radical hydrofluorination conditions developed by Boger and coworker.

The reaction, performed at $0{ }^{\circ} \mathrm{C}$, shows great tolerance to various functional groups, air, and even water, but uses an overstoichiometric amount of iron. The reaction times are short ( $30 \mathrm{~min}$.) which is particularly interesting for ${ }^{18} \mathrm{~F}$ labelling, as well as the use of $\mathrm{NaBH}_{4}$ as the hydride source that can be replaced by readily available $\mathrm{NaBD}_{4}$ for deuterium incorporation. This helped the authors determine that the addition is not diastereospecific.

Shigehisa and coworkers reported in 2013 another radical hydrofluorination of olefins that is catalyzed by a cobalt complex. ${ }^{[26]}$ Similarly to Boger's method, the functional group tolerance is quite extended with good compatibility to fluoridesensitive and acid-sensitive groups such as silyl ether, PMB, acetal and Boc (Scheme 16). The radical fluorine is delivered by $\mathrm{N}$-fluoro-2,4,6-trimethylpyridinium tetrafluoroborate $\left(\mathrm{NFCO} \cdot \mathrm{BF}_{4}\right)$, and 1,1,3,3-tetramethyldisiloxane is used as a radical hydrogen source.
Figure 5. Catalytic cycle proposed by Yin and coworkers for the enantioselective hydrofluorination of styrene derivatives

\section{Radical hydrofluorination}

It was demonstrated in 2012 that electrophilic reagent based on the $\mathrm{N}-\mathrm{F}$ bond could be used in a radical pathway. ${ }^{[24]}$ This quickly led to a new field of research on fluorination. Later that 


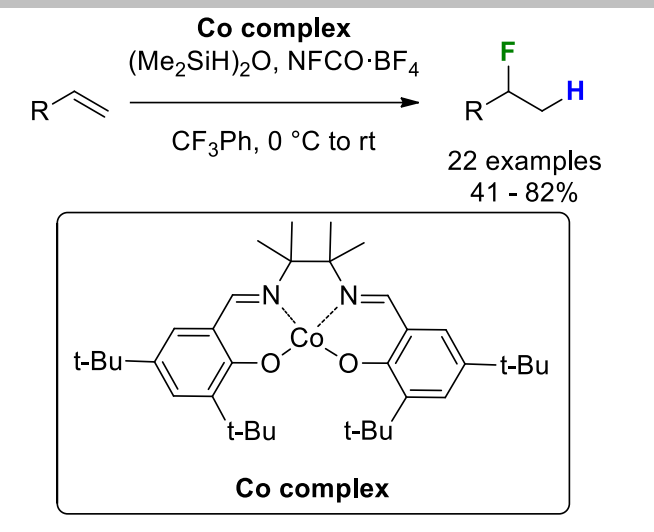

Selected examples<smiles>COc1cc(CC(C)F)ccc1OS(C)(=O)=O</smiles><smiles>CC(F)CC1OCCCO1</smiles>

$80 \%$

$78 \%$<smiles>[R]OC(C)C(F)CC</smiles><smiles>CN(CC1CCCC1F)C(=O)OC(C)(C)C</smiles>

$\mathrm{R}=\mathrm{PMB}, 60 \%$

$\mathrm{R}=\mathrm{TBS}, 82 \%$

$\mathrm{R}=\mathrm{Ts}, 75 \%$

addition of HF to afford homobenzylic fluoride via a photoredox pathway. An acridinium based photocatalyst was used in the presence of triethylamine trihydrofluoride and 4nitrophenyldisulfide (Scheme 17). The isolated yields are somewhat lower than the one calculated by NMR, which the authors attributes to the volatility of the products.

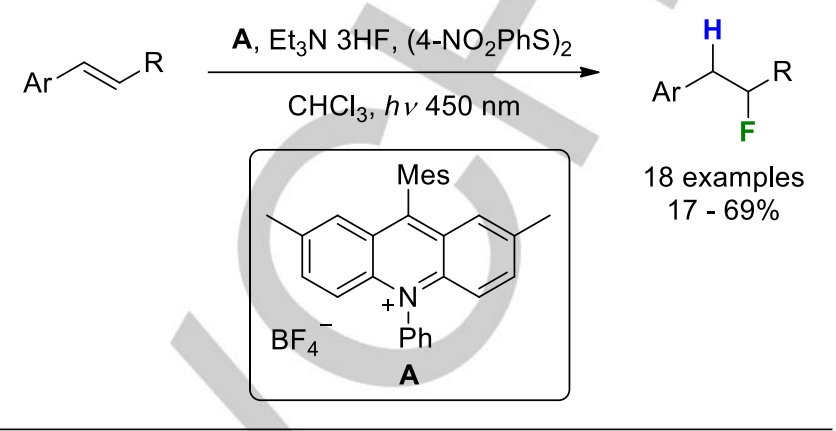

$$
\text { Selected examples }
$$

Scheme 16. Hydrofluorination conditions developed by Shigehisa and coworkers.

The authors propose a mechanism which involves a $\mathrm{Co}(\mathrm{II}) / \mathrm{Co}$ (III) redox couple. The fluoropyridinium serves as the oxidant and as the source of "F"" (Figure 6). The reaction can be run on a 1-gram scale without significant decrease of yield.
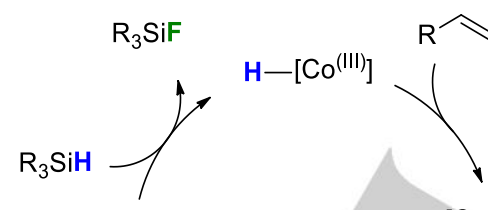

$$
\mathrm{F}-\left[\mathrm{Co}^{(\mathrm{III})}\right]
$$

$$
\left[\mathrm{Co}^{(\mathrm{III})}\right]
$$

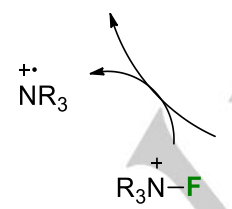
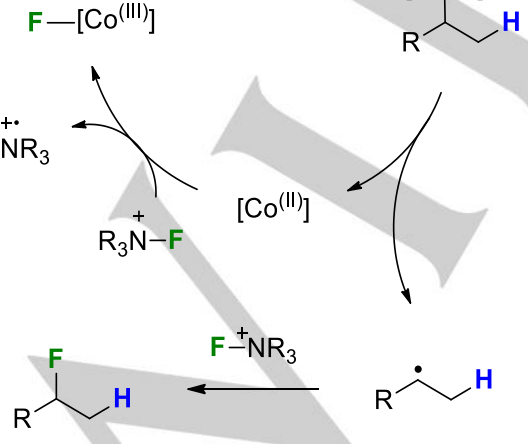

$\overbrace{}^{\circ} H$

Figure 6. Catalytic cycle proposed by Shigehisa and coworkers for the cobalt catalyzed hydrofluorination of alkenes.

Nicewicz and coworkers reported in 2014 an antiMarkovnikov addition of different mineral acids to styrene. ${ }^{[27]}$ Among the different acid tested, they reported a system for the
Scheme 17. Anti-Markovnikov hydrofluorination of styrene derivatives reported by Nicewicz and coworkers.

The reaction is initiated via an electronic excitation of the photocatalyst $\mathbf{A}$ by visible light. A photoinduced electron-transfert (PET) can then take place from the alkene to the activated photocatalyst. The radical cation formed on the substrate can then be fluorinated by triethylamine trihydrofluoride to afford the radical alkyl fluoride. In the meantime, the disulfide can be cleaved homolytically to form a radical thiophenol, that can be reduced to thiophenolate by regenerating the photocatalyst. The thiophenolate is then protonated with the acidic proton of the HF on the triethylamine. This hydrogen is then transfer to the radical alkyl fluoride to afford the hydrofluorination product (Figure 7). 


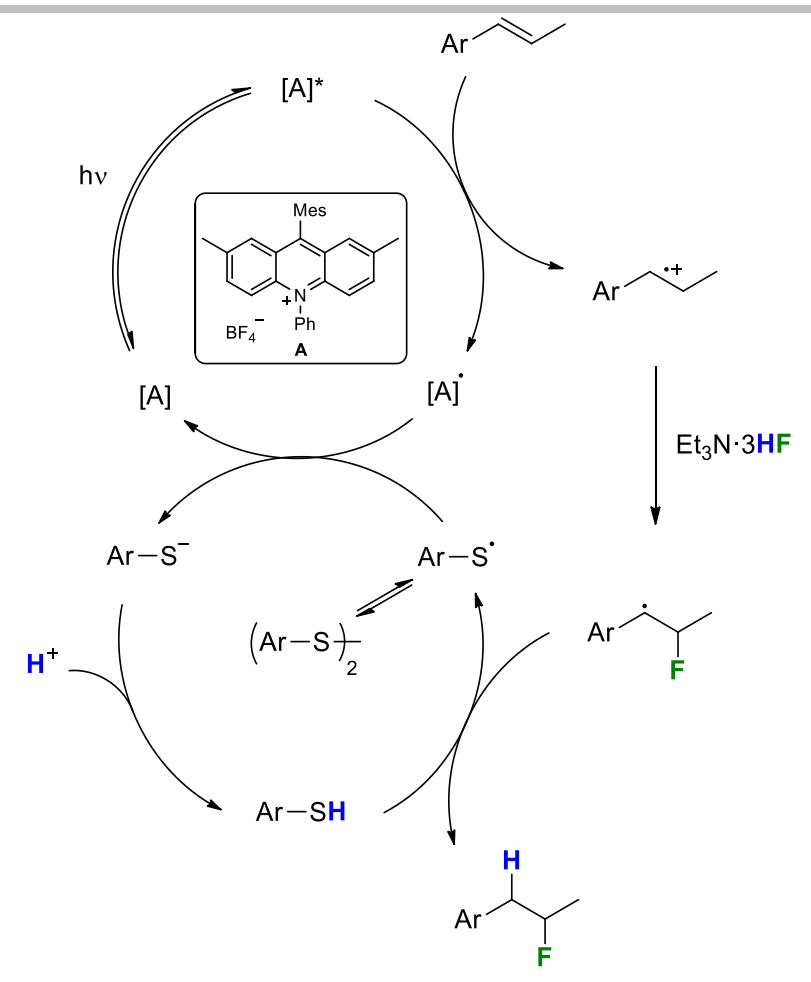

Figure 7. Catalytic cycle proposed by Nicewicz and coworkers for the antiMarkovnikov addition of HF to styrene derivatives.

In 2018, Zipse and Renaud reported a new class of reagents suitable for radical fluorination. ${ }^{[28]}$ Based on the N-F bond, these reagents show bond dissociation energies that are 30 to $45 \mathrm{~kJ} / \mathrm{mol}$ lower than more common reagent such as NFSI or Selectfluor. To examine the potential of these $\mathrm{N}$-fluoro- $\mathrm{N}$-arylsulfonamides, they performed a hydrofluorination of alkene via a two-step mechanism. Catecholborane is first added on the alkene to hydroborate the compound, which is then fluorinated with the reagent. The net product is an anti-Markovnikov hydrofluorination. The yields are good, ranging from $48 \%$ to $68 \%$ (Scheme 18). The authors also showed some interesting rearrangement through radical cyclization or cyclopropane openings.
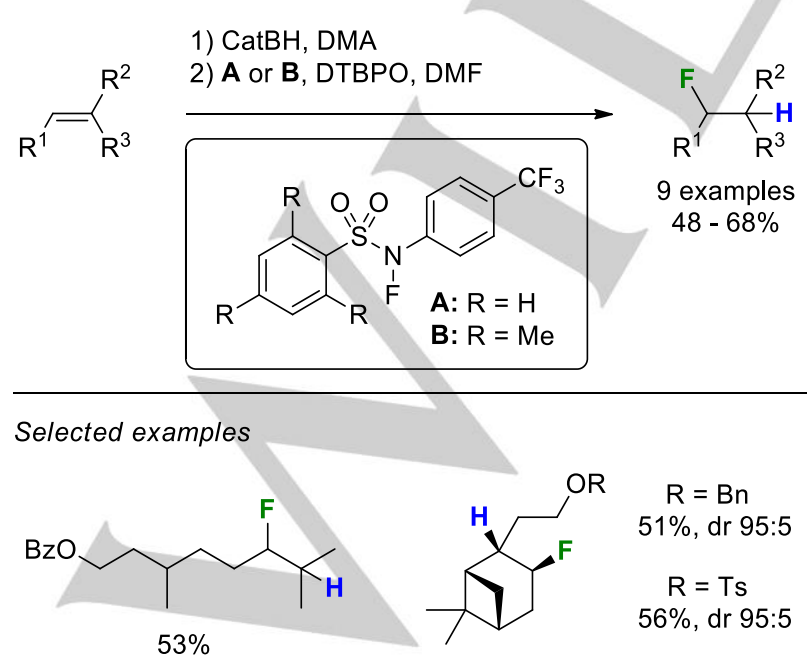

Scheme 18. Two-step hydrofluorination reported by Zipse and Renaud in 2018.
Another iron (III) catalyzed hydrofluorination was reported in 2019 by Ye and coworkers. Using a specific multidentate ligand, they were able to reduce the quantity of iron to only $5 \mathrm{~mol} \%$ (Scheme 19). ${ }^{[29]}$
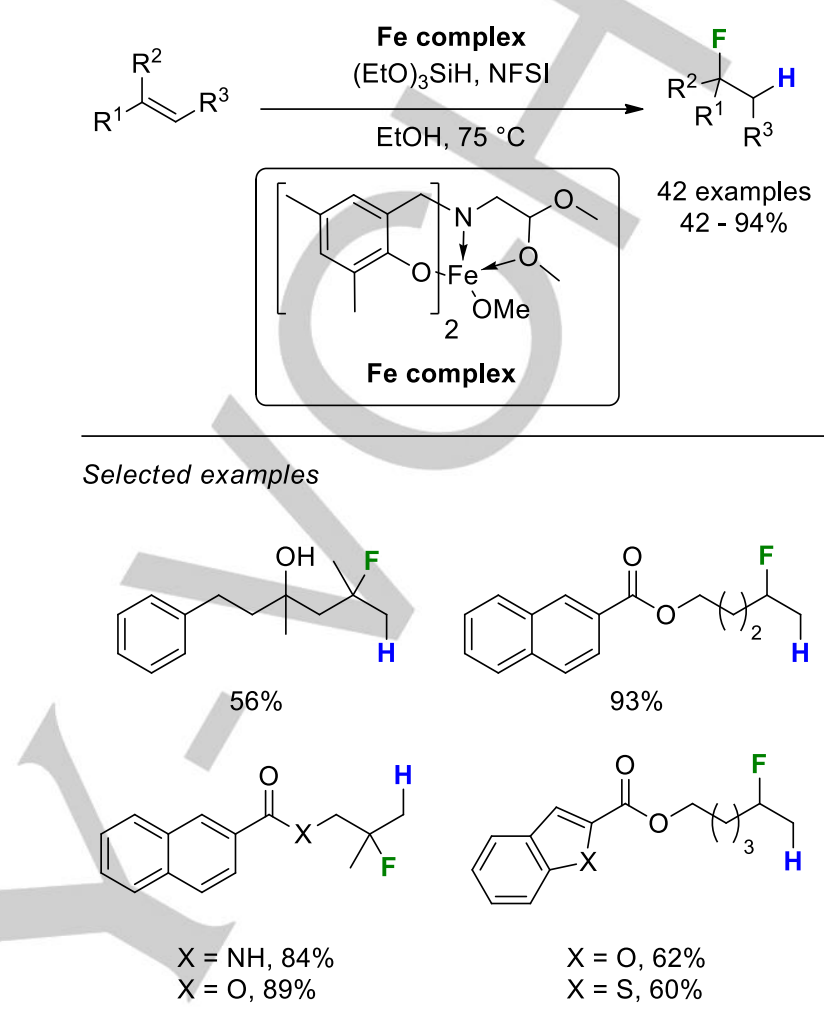

Scheme 19. Hydrofluorination conditions developed by Ye and coworkers

After screening the different sources of fluorine and hydrogen, they found that $\mathrm{N}$-fluorobenzenesulfonimide (NFSI) and triethoxysilane were the best options. The multidentate ligand proved essential for the catalytic amount of iron. They found an elegant way to regenerate the catalyst, using the radical formed on the benzenesulfonimide to oxidize the iron(II) to iron(III) (Figure 8). 


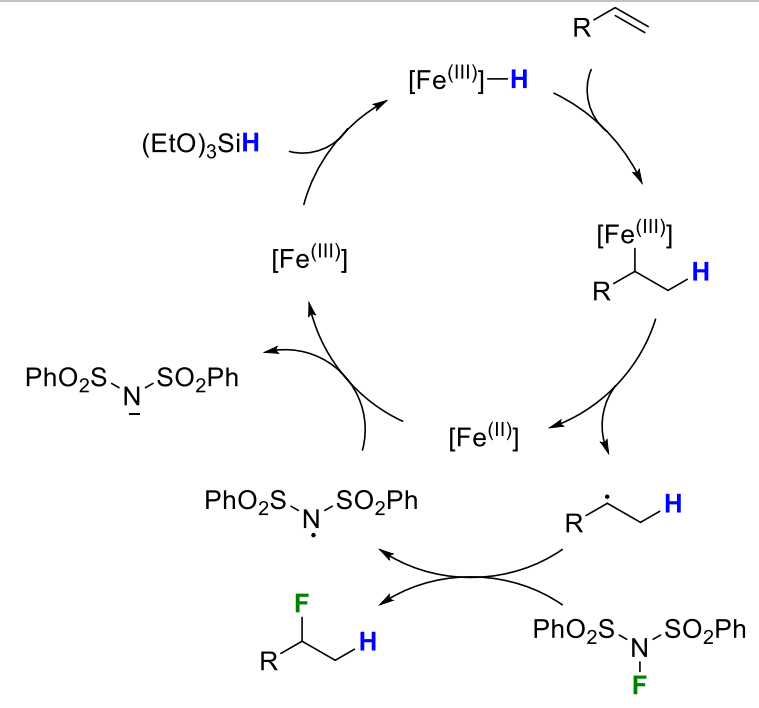

Figure 8. Catalytic cycle proposed by Ye and coworkers for the iron catalyzed hydrofluorination of alkenes.

Zhu and coworker reported a nickel-catalyzed hydrofluorination in 2020. ${ }^{\text {[0] }}$ They showed that nickel(II) nitrate hexahydrate in the presence of diethoxy(methyl)silane and NFSI could afford the desired fluorinated compound in good yields (Scheme 20). The reaction works well with mono-, di- and trisubstituted alkenes, and has a great chemical compatibility. Notably, easily reduced functional group such as aldehydes are tolerated as well as aryl chlorides, bromides, iodides, triflates and boronic ester which do not take part in any cross-coupling reaction. The reaction also tolerates air and water without significant loss of yields.

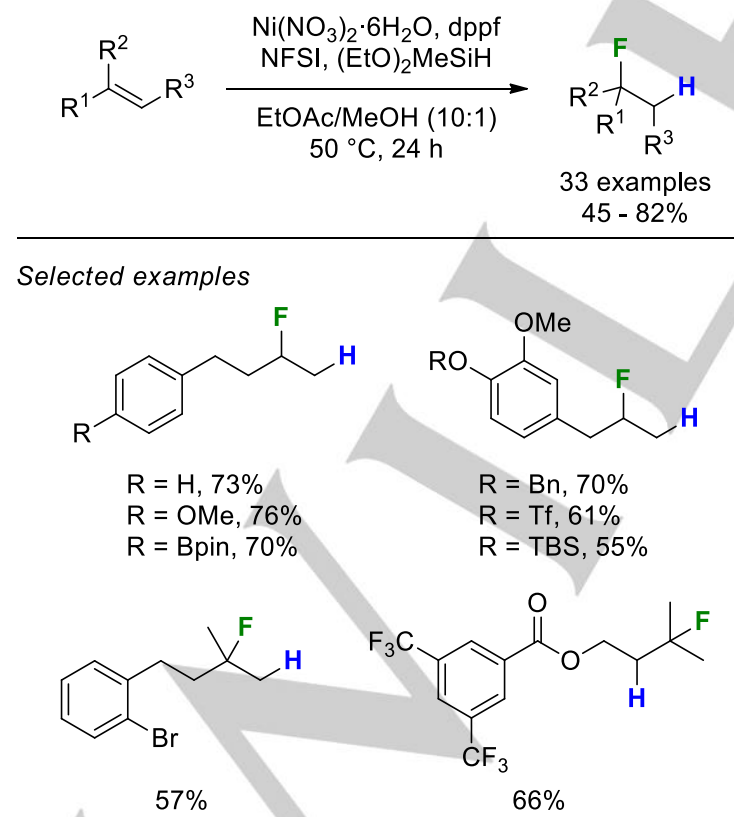

Scheme 20. Hydrofluorination conditions developed by Zhu and coworker.
The proposed mechanism proceeds through a hydrogen atom transfer from a Ni(III)-H species to the alkene to form the alkyl radical, that can then react with the NFSI to afford the fluorinated product. The $\mathrm{Ni}(\mathrm{III})$ can then be regenerate by reduction of the benzenesulfonimide radical (Figure 9 ).

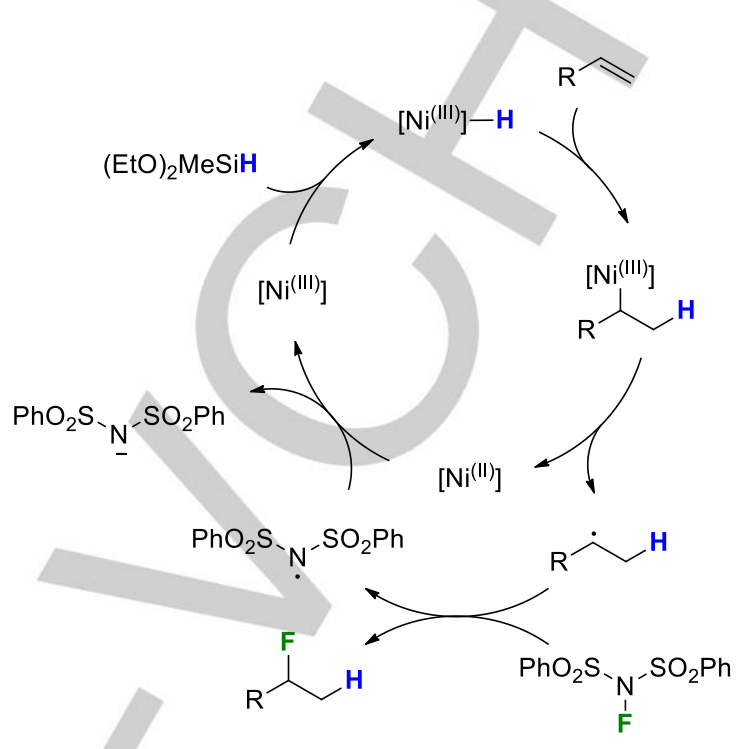

Figure 9. Catalytic cycle proposed by Zhu and coworker for the nickel catalyzed hydrofluorination of alkenes.

\section{Conclusion}

Since the first reported hydrofluorination of alkene using anhydrous hydrogen fluoride in 1938, many methods have been described to improve this reaction. Not only has safety been largely improved, but the functional tolerance as well as the yields of the reaction has been enhanced considerably. The development of three main mechanisms for this reaction allows for a large coverage of functionality, enabling the fluorination of wide variety of molecules. One of the remaining challenges of hydrofluorination of alkene is the chiral incorporation of the fluorine atom. Some examples have been reported by Gouverneur, MacMillan, Huang and Lei and Liao. Those reactions are, however, limited to specific type of alkene such as styrene or $\alpha, \beta$-insaturated aldehydes. Therefore, the development of an enantioselective hydrofluorination of a wide range of alkenes would be a considerable breakthrough in the fields.

\section{Acknowledgements}

We thank the Natural Sciences and Engineering Research Council of Canada (NSERC), le Fonds de recherche du Québec - Nature et technologies (FRQNT), and Université Laval.

Keywords: hydrofluorination $\cdot$ alkene $\cdot$ hydrogen fluoride $\bullet$ organofluorine compounds $\bullet$ synthetic methodologies

[1] For selected reviews and books, see: (a) Prakash, G. K. S.; Wang, F. Chim Oggi-Chem. Today 2012, 30, 30-XXX. (b) Thayer, A. M. Chem. Eng. News 2006, 84, 15-XXX. (c) Richardson, P. Expert. Opin. Drug Dis. 2016, 11 , 983-XXX. (d) Gouverneur, V.; Muller, K. Fluorine in Pharmaceutical and 
Medicinal Chemistry: From Biophysical Aspects to Clinical Applications, 1st ed., Imperial College Press, London, 2012. (e) Godhaviya, P.K. Studies of Fluorine: History, Application, water Fluoridation, Organo Fluorine, 1st ed., CreateSpace Independent Publishing Platform, 2015. (f) Zhou, Y.; Wang J.; Gu, Z.; Wang, S.; Zhu, W.; Aceña, J. L.; Soloshonok, V. A.; Izawa, K.; Liu, H. Chem. Rev. 2016, 116, 422-XXX. (g) Haufe, G.; Leroux, F. R. Fluorine in Life Sciences: Pharmaceuticals, Medicinal Diagnostics, and Agrochemicals: Progress in Fluorine Science Series, 1st ed., Academic Press, 2018. (h) Zhu, Y.; Han, J.; Wang, J.; Shibata, N.; Sodeoka, M.; Soloshonok, V. A.; Coelho, J. A. S.; Toste, F. D. Chem. Rev. 2018, 118, 3887-XXX. (i) Mei, H.; Han, J.; Fustero, S.; Medio-Simon, M.; Sedgwick, D. M.; Santi, C.; Ruzziconi, R.; Soloshonok, V. A. Chem. Eur. J. 2019, 25, 11797-XXX. (j) Purser, S.; Moore, P. R.; Swallow, S.; Gouverneur, V. Chem. Soc. Rev. 2008, 37, 320-XXX. (k) Kirk, K. L. Org. Proc. Res. Dev 2008, 12, 305-XXX. (I) Müller, K.; Faeh, C.; Diederich, F. Science 2007, 317, 1881-XXX. (m) Gillis, E. P.; Eastman, K. J.; Hill, M. D.; Donnelly, D. J.; Meanwell, N. A. J. Med. Chem. 2015, 58, 8315-XXX. (n) Meanwell, N. A. J. Med. Chem. 2018, 61, 5822-XXX.

[2] For selected reviews, see: (a) Fujiwara, T.; O'Hagan, D. J. Fluorine Chem. 2014, 167, 16-XXX. (b) Jeschke, P. Pest. Manag. Sci. 2010, 66, 10-XXX. (c) Paznok, S.; Leroux, F. R. Modern Fluorine-Containing Agrochemicals. In Frontiers of Organofluorine Chemistry, 2020, pp 695-732.

[3] For selected reviews and articles, see: (a) Berger, R.; Resnati, G.; Metrangolo, P.; Weber, E.; Hulliger, J. Chem. Soc. Rev. 2011, 40, 3496XXX. (b) Vincent, J.-M. Chem. Commun. 2012, 48, 11382-XXX. (c) Fang C.; Jing, Y.; Zong, Y.; Lin, Z. J. Fluorine Chem. 2016, 192, 113-XXX.

[4] For selected reviews see : (a) Wu, J. Tetrahedron Lett. 2014, 55, 42894294. (b) Ni, C.; Hu, J. Chem. Soc. Rev. 2016, 45, 5441-5454. (c) Yerien, D. E.; Bonesi, S.; Postigo, A. Org. Biomol. Chem. 2016, 14, 8398-8427. (d) Yang, X.; Wu, T.; Phipps, R. J.; Toste, F. D. Chem. Rev. 2015, 115, 826870. (e) Szpera, R.; Moseley, D. F. J.; Smith, L. B.; Sterling, A. J.; Gouverneur, V. Angew. Chemie Int. Ed. 2019, 58, 14824-14848. (f) Neumann, C. N.; Ritter, T. Angew. Chemie Int. Ed. 2015, 54, 3216-3221. (g) Champagne, P. A.; Desroches, J.; Hamel, J. D.; Vandamme, M.; Paquin, J. F. Chem. Rev. 2015, 115, 9073-9174.

[5] Inoue, M.; Sumii, Y.; Shibata, N. ACS Omega 2020, 5, 10633-10640.

[6] Grosse, A. V.; Linn, C. B. J. Org. Chem. 1938, 3, 26-32.

[7] Olah, G. A.; Nojima, M.; Kerekes, I. Synth. 1973, 779-780.

[8] (a) Yoneda, N.; Abe, T.; Fukuhara, T.; Suzuki, A. Chem. Lett. 1983, 12, 1135-1136. (b) Yoneda, N.; Nagata, S.; Fukuhara, T.; Suzuki, A. Chem. Lett. 1984, 13, 1241-1242.

[9] Olah, G. A.; Li, X.-Y. Synlett 1990, 267-269.

[10] Bucsi, I.; Török, B.; Marco, A. I.; Rasul, G.; Prakash, G. K. S.; Olah, G. A. J. Am. Chem. Soc. 2002, 124, 7728-7736.

[11] Tamura, M.; Shibakami, M.; Kurosawa, S.; Arimura, T.; Sekiya, A. J. Chem. Soc., Chem. Commun. 1995, 18, 1891-1892

[12] Hara, S.; Kameoka, M.; Yoneda, N. Synlett 1996, 529-530.

[13] (a) Thibaudeau, S.; Martin-Mingot, A.; Jouannetaud, M. P.; Karam, O.; Zunino, F. Chem. Commun. 2007, 30, 3198-3200. (b) Liu, F.; MartinMingot, A.; Jouannetaud, M. P.; Karam, O.; Thibaudeau, S. Org. Biomol. Chem. 2009, 7, 4789-4797.

[14] Vardelle, E.; Gamba-Sanchez, D.; Martin-Mingot, A.; Jouannetaud, M. P.; Thibaudeau, S.; Marrot, J. Chem. Commun. 2008, 12, 1473-1475.

[15] Lu, Z.; Zeng, X.; Hammond, G. B.; Xu, B. J. Am. Chem. Soc. 2017, 139, 18202-18205.

[16] Lu, Z.; Bajwa, B. S.; Otome, O. E.; Hammond, G. B.; Xu, B. Green Chem. 2019, 21, 2224-2228.

[17] Bertrand, X.; Paquin, J. F. Org. Lett. 2019, 21, 9759-9762.

[18] Wilkinson, J. A. Chem. Rev. 1992, 92, 505-519.

[19] Lal, G. S.; Pez, G. P.; Syvret, R. G. Chem. Rev. 1996, 96, 1737-1755.

[20] Huang, Y.; Walji, A. M.; Larsen, C. H.; Macmillan, D. W. C. J. Am. Chem. Soc. 2005, 127, 43, 15051-15053

[21] Emer, E.; Pfeifer, L.; Brown, J. M.; Gouverneur, V. Angew. Chemie Int. Ed. 2014, 53, 4181-4185.

[22] Wang, L.; Jiang, X.; Chen, J.; Huang, Y. Angew. Chemie Int. Ed. 2019, 58, 7410-7414.

[23] Yin, X.; Chen, B.; Qiu, F.; Wang, X.; Liao, Y.; Wang, M.; Lei, X.; Liao, J. ACS Catal. 2020, 10, 1954-1960.
[24] Rueda-Becerril, M.; Chatalova Sazepin, C.; Leung, J. C. T.; Okbinoglu, T.; Kennepohl, P.; Paquin, J. F.; Sammis, G. M. J. Am. Chem. Soc. 2012, 134, 4026-4029.

[25] Barker, T. J.; Boger, D. L. J. Am. Chem. Soc. 2012, 134, 13588-13591.

[26] Shigehisa, H.; Nishi, E.; Fujisawa, M.; Hiroya, K. Org. Lett. 2013, 15, 51585161.

[27] Wilger, D. J.; Grandjean, J.-M. M.; Lammert, T. R.; Nicewicz, D. A. Nat. Chem. 2014, 6, 720-726.

[28] Meyer, D.; Jangra, H.; Walther, F.; Zipse, H.; Renaud, P. Nat. Commun. 2018, 9, 1-10

[29] Xie, Y.; Sun, P.; Li, Y.; Wang, S.; Ye, M.; Li, Z. Angew. Chemie Int. Ed. 2019, 58, 7097-7101.

[30] Song, P.; Zhu, S. ACS Catal. 2020, 10, 13165-13170. 


\section{Entry for the Table of Contents}

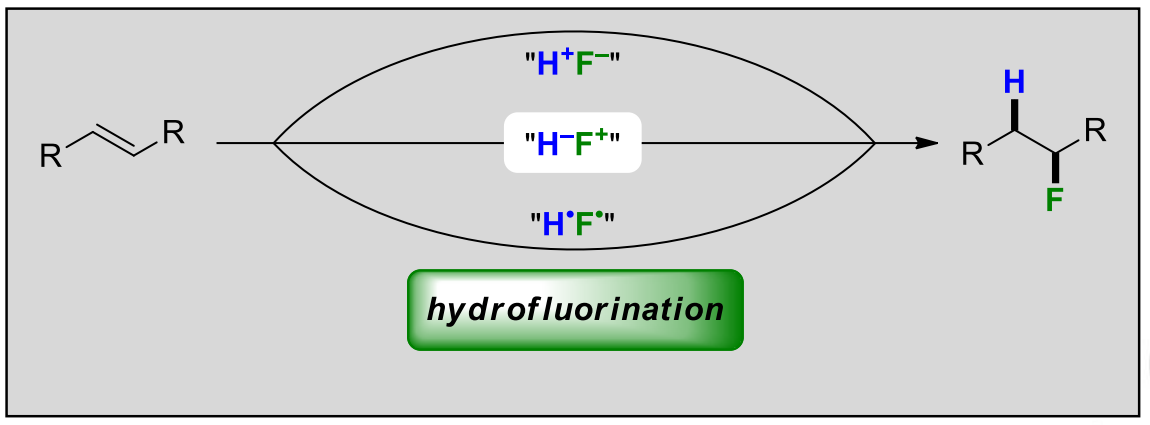

Hydrofluorination of alkene has become a powerful tool for the incorporation of a single fluorine atom, which are useful in a vast array of chemical fields. This review presents the development in this area from the first reported addition to the most recent examples, separated into the three main possible mechanism: nucleophilic, electrophilic, and radical hydrofluorination.

Institute and/or researcher Twitter usernames: @jfluorine 